\title{
Arte e reciclagem: Diálogos com a educação básica
}

\section{Art and recycling: Dialogues with basic education}

DOI: $10.46814 / 1 a j d v 4 n 1-013$

Recebimento dos originais: 01/01/2021

Aceitação para publicação: 28/02/2022

\section{Prof.Dr.Alfredo Oscar Salun}

Doutor em História Social (USP)

professor do curso Educação em Direitos Humanos IUFABC e de História ContemporânealUninove.

Orientador de projetos pedagógicos na SEESP e pesquisador do NEHOIUSP e GEINT.

Autor dos livros: Zé Carioca vai a Guerra (Editora Pulsar); Revolucionários ou tiranos (Editora

Todas as Musas) e Corinthians e Palestra Itália: Futebol em terras Bandeirantes (Editora Todas as

Musas).

E-mail: aosalun@uol.com.br

\section{RESUMO}

Neste artigo estamos refletindo sobre a relação de arte e reciclagem com a educação básica, visualizando a escola como espaço de conscientização social frente aos problemas ocasionados pela superprodução e a exploração excessiva dos recursos naturais. Entrevistamos professores da rede pública paulista e apontamos como trabalhos com materiais recicláveis podem contribuir na promoção da cidadania.

Palavras-chave: Educação, arte, reciclagem e história oral.

\section{ABSTRATIC}

In this article, we are reflecting on the relationship between art and recycling and basic education, viewing the school as a space for social awareness in the face of problems caused by overproduction and the excessive exploitation of natural resources. We interviewed public school teachers in São Paulo and pointed out how work with recyclable materials can contribute to the the promotion of citizenship.

Keywords: Education, art, recycling and oral history.

\section{INTRODUÇÃO}

Desde que o homem se constituiu em sociedade utilizou sua capacidade de trabalho para modificar a natureza, entretanto, nas últimas décadas, o estágio da exploração tem aumentado vertiginosamente em função do desenvolvimento industrial e do consumismo. Isso significa que dentre os grandes problemas que atualmente assolam a humanidade, podemos citar a questão da fome, desigualdade social, desequilíbrio ambiental e a poluição em suas várias facetas.

Aos poucos a sociedade tem compreendido que a intervenção excessiva do ser humano no planeta, pode afetar de maneira irrecuperável a natureza e colocar em perigo a sobrevivência dos 
sistemas sociais. Apesar de China e EUA representarem modelos políticos distintos, suas práticas comerciais e produtivas são bem próximas, resultando nos maiores índices de crescimento econômico na história da humanidade. Infelizmente atendem muito mais aos interesses de grupos dirigentes e empresariais, preocupados com o aumento da produção e do lucro, do que as reais demandas do conjunto da sociedade.

Os defensores do capitalismo afirmavam que o progresso e a harmonia seriam alcançados graças ao livre mercado que permitiria o crescimento da riqueza e sua melhor distribuição. Após a Segunda Guerra Mundial, Friedrich von Hayek, Milton Friedman e a denominada "Escola de Chicago" retomaram a defesa do liberalismo econômico e a visão do mercado como indutor de riquezas. Destacavam que o papel do Estado deveria se restringir a fiscalizar o sistema capitalista, estabelecendo condições para a competição e combatendo monopólios. Dessa forma, apostavam que com o crescimento econômico seria possível aliviar a extrema pobreza, na medida em que os trabalhadores estariam se beneficiando com o aumento da oferta de emprego e da estabilidade. (FRIEDMAN, 1982)

Entretanto esse modelo as vezes denominado como "neoliberal" nunca se mostrou efetivo na diminuição da desigualdade e pobreza, e chegamos ao século XXI com o aumento da concentração de renda e do fosso social. Utilizando os dados disponibilizados pelas principais organizações mundiais, Carlos Gonçalves (2012) apontou que os $20 \%$ dos habitantes mais ricos do planeta consumiam cerca de $85 \%$ da matéria prima e energia produzidas anualmente. Na lista publicada pela Forbes e outras revistas comerciais em 2016 sobre os dois mil indivíduos mais ricos do mundo, chegava-se a conclusão de que possuíam mais riqueza em conjunto do que os setenta por cento mais pobres da humanidade. ${ }^{1}$

A concentração de riqueza é um fenômeno mundial, usando como exemplo os EUA e China, que em conjunto dominam mais de $40 \%$ do comércio mundial, também são os países que possuem o maior número de bilionários. E com a pandemia do Covid19 os bilionários ao redor do mundo aumentaram suas fortunas e as camadas mais pobres viram piorar sua condição de vida. Em 2021 os dados apontam que $38 \%$ da população brasileira está abaixo da linha da pobreza, em um movimento inverso ao que ocorreu em governos de centro-esquerda, quando a ONU destacou os projetos sociais que retiraram o país do "mapa da fome". ${ }^{2}$

Obviamente a desigualdade social não é uma novidade na história da humanidade, a Organização das Nações Unidas (ONU) e a Organização Internacional do Trabalho (OIT) em relatório conjunto produzido em 2004 já destacava que a crescente diferenciação entre indivíduos, também se aplicava entre países ricos e pobres. É visível que está ocorrendo uma superconcentração de riqueza

\footnotetext{
${ }^{1}$ https://forbes.com.br/listas/2016/03/70-maiores-bilionarios-do-mundo-em-2016/. Acesso em 02.12.2018

2 https://www.unicef.org/brazil/comunicados-de-imprensa/relatorio-da-onu-ano-pandemico-marcado-por-aumento-dafome-no-mundo. Acesso em 12.09.2021
} 
como alertou Thomas Piketty (2014), isso significa que os setores remediados, classe média e principalmente os mais vulneráveis tem assumido os custos relativos a essa situação. Ele recomenda a adoção do "imposto progressivo sobre renda", "imposto sobre grandes fortunas" e um "Estado social para o século XXI". Não é coincidência que o atual presidente dos Estados Unidos Joe Biden em seu discurso de posse em 2021, anunciou a necessidade de medidas para amenizar a desigualdade social no país e melhorar as condições de vida das camadas sociais mais vulneráveis.

Não é necessário muito esforço para verificar que o paulatino aumento da riqueza produzida no mundo, não acarretou o enriquecimento geral da população. E, mesmo que milhares de pessoas se encontrem abaixo da linha de pobreza e alijada do consumo, o desequilíbrio social também tem imbricações ambientais:

\begin{abstract}
A sociedade capitalista urbano-industrial e seu modelo de desenvolvimento econômico e tecnológico tem causado crescente impacto sobre o ambiente e a percepção desse fenômeno vem ocorrendo de maneiras diferentes por ricos e pobres..... população de baixa renda tem vivido diretamente os impactos de problemas ambientais e tal fato acaba por aumentar suas dificuldades cotidianas, expressa pela falta de agua, espaços habitacionais seguros, alimentação etc.... (PHILIPPI JR e PELICIONI, 2005, p.7)
\end{abstract}

Diversas entidades públicas, organizações sociais e intelectuais passaram a denunciar o esgotamento dos recursos naturais, o problema do lixo e do consumo excessivo. Nas últimas décadas temas como meio ambiente e sustentabilidade foram inseridas paulatinamente nos conteúdos curriculares na educação básica, cujo objetivo é estimular uma relação mais saudável entre o homem e a natureza.

Na década de 1970 os temas ambientalistas foram abordados em vários seminários e congressos quando se iniciou de forma mais sistemática o estudo e a incorporação das variáveis ambientais nas tomadas de decisão governamental. Ao longos das décadas seguintes se realizaram negociações internacionais sobre o clima, que culminaram com protocolos, nem sempre respeitados que propôs a adoção de medidas de controle e sanções em relação a emissão de gases de efeito estufa (GES).

De acordo com Cardoso (2006) existe uma conexão entre poluição ambiental, alterações climáticas e desastres naturais que assolam o planeta, já que o aquecimento global estaria sendo causado pela ação humana. Segundo o relatório Key GHG Data publicado em novembro de 2005 na Convenção das Nações Unidas sobre o efeito estufa, os principais países poluentes eram justamente os mais ricos do globo como EUA e China, seguidos de perto nessa classificação desabonadora pela Rússia. Evidentemente, com retrocessos e avanços, esses mesmos países tem discutido medidas para constituírem um mundo "mais saudável e sustentável” nos últimos anos 3 .

\footnotetext{
${ }^{3}$ https://www.dw.com/pt-br/eua-e-china-prometem-cooperar-pelo-clima/a-57244352. Acesso em 03.08.2021
} 
A oposição ao ideário consumista pode ser percebida nos anos 1960 em manifestações realizadas por estudantes e ativistas sociais, que trouxeram para o grande público um debate importante, e que dentro de alguns limites, hoje faz parte da agenda do século XXI. E, mesmo que a maioria dos responsáveis pelos setores produtivos não estejam imbuídos de uma preocupação social ou ambiental, verificamos que vários empresários demonstram outro perfil, buscando atender as exigências dos consumidores engajados na defesa social e ambiental.

Assim, temos por exemplo o Pacto Global desenvolvido por agencias das Nações Unidas que objetiva mobilizar a comunidade empresarial para adotar em suas práticas, valores internacionalmente aceitos em relação ao meio ambiente, combate a corrupção, respeito aos direitos humanos e dos trabalhadores. No Brasil, iniciativas como o "selo verde" ou ecos-selos" de acordo com Sebrae, auxiliam os consumidores na decisão de suas compras ao certificar as empresas que possuam

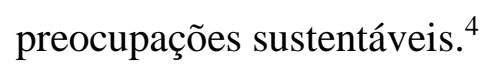

Apesar do crescente debate mundial que estava em voga na década de 1960, no Brasil ocorreu o inverso segundo Andrea Pelicioni (2005), pois a discussão foi prejudicada pela ditadura de 1964 que desmobilizou as ações de cidadania. Somente no final dos anos de 1970 o assunto ganhou destaque, fato que levou a criação de instrumentos para a preservação ambiental e o desenvolvimento sustentável. Em 1981 foi criada a Lei da Política Nacional de Meio Ambiente (PNMA) e no ano seguinte instituiuse o Conselho Nacional de Meio Ambiente (CONAMA) que tem por objetivo assessorar diretrizes e políticas ambientais e deliberar sobre normas e padrões para a manutenção de um ambiente equilibrado.

Foram criados outros instrumentos legais no sentido de proteger, preservar e recuperar o meio ambiente e o Poder Público tem como obrigações: cuidar do patrimônio genético, preservar e restaurar os processos ecológicos, definir áreas para proteção ambiental, controlar a produção e a comercialização de produtos que importem riscos à saúde, promover a educação ambiental, proteger a fauna e a flora e exigir o estudo de impacto ambiental para atividades potencialmente poluidoras.

Portanto, a luta pelo meio ambiente e economia sustentável tem sido defendido no Brasil por vários movimentos sociais e políticos, que tem como um dos seus expoentes a ex-senadora Marina Silva, que foi ministra do meio ambiente no governo Lula:

\footnotetext{
“...com raízes na trajetória de lutas do campo socioambiental, a REDE quer ser ponte entre as demandas por justiça e direitos sociais e humanos e o movimento contra o uso abusivo do ambiente natural, demonstrando que estes são inseparáveis..." 5
}

\footnotetext{
$4 \quad$ http://sustentabilidade.sebrae.com.br/sites/Sustentabilidade/Para\%E2\%80\%93sua\%E2\%80\%93Empresa/NucleoInteligencia/certificacoes-verdes,cc243a3a410ef510VgnVCM1000004c00210aRCRD. Acesso em 03.08.2021

5 https://www.poder360.com.br/wp-content/uploads/2018/02/Carta-Compromisso-entre-a-REDE-Sustentabilidade-e-oMovimento-Agora.pdf. Acesso em 21\06\2020.
} 
Em suma, ao adotar diversas medidas preventivas, o Brasil se tornou um dos países com a mais avançada legislação ambiental entre 1996-2018, entretanto com o Governo Jair Bolsonaro ocorreu um retrocesso vexatório que lhe valeu críticas internacionais dos mais variados setores.

\section{RECICLAGEM E EDUCAÇÃO}

Nessa conjuntura de defesa ambiental a educação da sociedade é muito importante, seja em relação aos adultos por meio de campanhas nos meios de comunicação de massa, assim como dos jovens, com a incorporação de temas ligados à questão da sustentabilidade como conteúdo na educação básica e em diversos cursos do ensino superior, como foi apontado por Pedro Jacobi (1997) ao destacar sua importância no século XXI na promoção da educação para a cidadania.

Apesar dos discursos oficiais desde a redemocratização, quando se acreditava que a educação básica com qualidade seria uma prioridade das camadas dirigentes, verificamos como o tema foi relegado na prática. Quando refletimos sobre a universalização da escola pública no Brasil e os primeiros passos na adoção da jornada de tempo integral, devemos conceber que não seja somente para ampliar a quantidade de horas que o aluno passa na Unidade Escolar, mas também, é imprescindível a qualidade do que é ofertado.

Parece ser óbvio conclamar que expansão e qualificação caminhem em conjunto, entretanto a história da educação no Brasil demonstra uma trajetória bifurcada, pois a melhoria efetiva da rede como um todo requer investimentos, planejamento, valorização do professor, competência gerencial dos governantes e participação da comunidade.

A formação dos jovens perpassa por diferentes competências e habilidades que incluem não apenas o lado tecnológico e profissional, mas também o desenvolvimento social, convívio e respeito para com o outro. Dessa forma, oficinas e cursos sobre práticas sustentáveis que englobem cozinha, artesanato, jardinagem, construção, cidadania, reciclagem, saúde e separação do lixo, por exemplo.

De acordo com Maria Helena Sponton (2005) o mundo precisa urgentemente reencontrar a harmonia entre a natureza e a humanidade, nesse aspecto a parte artística tem um papel importante ao sensibilizar pessoas sobre a importância do respeito e da preservação, ou mesmo da recuperação do que já foi destruído.

Acreditamos que cursos itinerantes em toda rede com educadores e artistas, que discutam teoricamente as mazelas do consumismo e do desperdício, e que na prática desenvolvam a sensibilidade artística dos alunos com trabalhos manuais, possam gerar frutos interessantes e contribuir para a formação global.

Sabemos que a reutilização de resíduos recicláveis e a coleta seletiva estão incorporadas nos projetos educacionais e que se tornaram modelos de trabalhos integrados, com exposições, feiras e 
outras atividades. Entretanto, são exemplos pontuais que ganham em algumas ocasiões prêmios e a cobertura dos meios de comunicação, mas que não representam a realidade das diversas redes estaduais ou municipais "como um todo".

A educação ambiental e o debate em torno do papel do individuo e da sua comunidade, é de acordo com Anna Brasil e Fátima Santos (2007) um assunto candente, pois o lixo é um grande provocador da poluição, já que em função da complexidade das atividades humana, a produção de lixo tem aumentado assustadoramente, sendo muitas vezes descartado e acumulado no meio ambiente.

O lixo domiciliar é formado por resíduos sólidos como papel, vidro, papelão plástico e principalmente de lixo orgânico, como restos de alimentos que em várias ocasiões são desperdiçados, e não existe um sistema adequado nas cidades brasileiras para atender essa demanda e seu destino final. Os lixões, aterros, incineração ou reciclagem, não conseguem impedir os impactos ambientais ocasionados, por isso, não devemos subestimar a participação do cidadão, mediante coleta seletiva, pois materiais como papeis, vidros, plásticos e metais podem ser usados na reciclagem.

Arte, reciclagem e educação, deveria ser tema importante para trabalhar com as crianças e adolescentes nas escolas, pois a conscientização do seu papel como agente transformador, surtiria mais efeito se iniciado nessa fase. Mas, os poucos projetos realizados no ambiente escolar se devem as iniciativas individuais, mesmo que os PCNS e as diretrizes curriculares apontem para a necessidade de propostas coletivas, que abarquem a rede como um todo:

O trabalho pedagógico de valorização da sustentabilidade deve, também, incluir a preocupação com os subprodutos do sistema produtivo, já que na maior parte das vezes suas atividades acabam gerando poluição. É necessário discutir as alternativas regionais e globais de administração dos problemas de poluição e produção de lixo, por serem alguns dos mais graves provocados pela ação do ser humano no meio ambiente. (SEAD. 1998, p 138)

\section{ENTREVISTAS COM PROFESSORES}

$\mathrm{Na}$ produção desse artigo entrevistamos alguns professores conforme orientações de José Carlos Sebe Bom Meihy (2005). Estes colaboradores são profissionais da rede pública do Estado de São Paulo e da capital paulista que realizam atividades com materiais recicláveis em suas unidades escolares. ${ }^{6}$

Temas como reciclagem, sustentabilidade e economia verde se tornaram parte do cotidiano escolar e a Secretaria Estadual de Educação implantou recentemente o Inova Educação. Mas, os trabalhos relacionados ao despertar da cidadania e consciência dos educandos, já vem sendo ofertados dentro das Unidades Escolares, dos quais estamos apontando algumas experiências. Nesse contexto, de acordo com o professor de Educação Artística Anésio Soares que desenvolveu entre 2006 e 2008,

\footnotetext{
${ }^{6}$ As entrevistas realizadas entre 2014 e 2016 neste projeto foram consentidas para divulgação pública.
} 
diversos trabalhos nas series iniciais do ensino fundamental II, onde utilizava embalagens de produtos para a confecção de brinquedos:

.....com os meninos, utilizamos as embalagens de creme dental para produzir carrinhos, na realidade, aprendi isso quando era criança, mediante um livro de artesanato que ensinava a utilizar esse material que seria descartado como lixo....também com as garrafas de pet ensinei algo bem tradicional, que foi elaborar abajur e outros enfeites para a casa. No final do semestre letivo, fazíamos uma exposição com a produção dos alunos e convidávamos a comunidade... era um trabalho bacana, mas infelizmente, abandonei a escola pública, em virtude dos baixos salários e das péssimas condições de trabalho. ${ }^{7}$

Francine Silva professora de Geografia na rede estadual na Grande São Paulo, aponta as mesmas dificuldades. Salienta que apesar da distribuição de materiais de consumo pela direção escolar e da existência de um laboratório de informática para utilização com os alunos, existem diversos outros problemas que decorrem da estrutura da rede que acaba afetando a sala de aula.

Na minha experiência nestes vinte e um anos de magistério, confesso que desmotiva muitos colegas, são as condições precárias de trabalho. A rede mudou, infelizmente, para pior. A questão não se resume em comprar material para distribuir aos alunos, livros, apostilas jornais, etc. Na realidade sabemos que isso, beneficia muito mais as empresas que tem contrato com o governo. A educação com qualidade está ligada primordialmente a um profissional motivado. Poderiam oferecer aos professores da rede, alguns benefícios que são oferecidos aos professores da USP. Como tempo para pesquisa ou congressos, e parte da carga horária ser dedicada a isso, para trazer ao aluno, novidades. Mas, com este salário ridículo e com tantas turmas, é impossível um trabalho com qualidade.

O que sobra é remediar a situação, aqui na escola fazemos atividades sobre coleta e reciclagem, assim como discutimos a questão da sustentabilidade nas aulas de geografia. ${ }^{8}$

\title{
A professora Jussara Rodrigues (formada em Educação Artística e pós-graduação em Letras)
}

desenvolve diversos trabalhos em artes, utilizando os recursos de informática nos laboratórios, destacou algumas questões semelhantes.

\begin{abstract}
Você não vê um professor da USP fazendo curso de capacitação exigido pela reitoria. Isso, porque ele está se capacitando na leitura, congresso, produção ou troca de experiência. Isso é possível, porque ele tem condições de trabalho, sua carga horaria permite um tempo livre, para que se dedique a sua formação continuada. Por outro lado, é algo dolorido. A escola pública atende a população mais pobre, as condições são precárias, tanto para o professor quanto para os alunos. A universidade pública atende majoritariamente, alunos oriundos de escolas particulares. Graças aos programas do governo do PT, como cotas e bolsas, tornou-se possível o ingresso de pessoas de classe desfavorecida no ensino superior. Entretanto, são as instituições privadas que abrigam os alunos pobres, e raramente se comparam com as instituições públicas no tocante a qualidade dos cursos. Ou seja, a boa educação no Brasil, é um privilégio para poucos, tanto na educação básica quanto no ensino superior. Em algumas escolas foi possível fazer projetos interdisciplinares, no meu caso especifico, como gosto de plantas participei com alunos na criação de hortas, e a produção de textos nas aulas de redação sobre os problemas ambientais do pais e principalmente da poluição nos centros urbanos. ${ }^{9}$
\end{abstract}

\footnotetext{
${ }^{7}$ Entrevista concedida ao autor em junho de 2015

${ }^{8}$ Entrevista concedida ao autor em março de 2015

${ }^{9}$ Entrevista concedida ao autor em agosto de 2014
} 
Também com formação em História e Educação Artística, Fatima Souza (já em processo de aposentadoria) se lamentou que seja uma das últimas concursadas na área de Educação Artística na SED-SP, fato que dificulta a troca de ideias dentre os docentes e que demonstra a falta de visão estratégica do poder público, especificamente o governo do Estado de São Paulo:

Infelizmente a questão da arte é pouco valorizada no currículo escolar, estamos no século XXI onde imaginávamos que os alunos deveriam ter uma formação completa, que abarcasse não apenas o raciocínio lógico, mas também sua sensibilidade. Mas, o que podemos esperar de um grupo político que se encontram tanto tempo no poder e que não estabeleceram a educação como um projeto de Estado?

Quando comecei a lecionar, as escolas estaduais tinham até laboratórios para arte e ferramentas elétricas, podíamos desenvolver diversos tipos de trabalho. Hoje, com toda importância da discussão sobre sustentabilidade, percebemos o quanto estamos longe da demanda social.

Realizo alguns projetos muito tímidos, dentro daquilo que poderia ser desenvolvido. Imagina, o quanto existe de empresas cooperadas de reciclagem espalhadas pela cidade que serviriam de um grande laboratório. Mas, falta uma coordenação maior entre as escolas e as diretorias de ensino. ${ }^{10}$

De maneira semelhante, o professor Márcio Bermutes (História) identifica as deficiências inerentes no desenvolvimento de projetos nas unidades escolares, mesmo que realize feiras e atividades interessantes, lastima que seja um procedimento individual e não um trabalho coletivo coordenado pelas diretorias de ensino:

Como leciono em uma escola de tempo integral na zona sul, consigo ficar mais tempo na unidade e integrar alguns alunos em propostas de conscientização. Uma delas, é a coleta seletiva, com a ajuda dos grêmios e outros interessados, fazemos diariamente a recolha de objetos jogados no chão e conversamos com os alunos, para alocar cada lixo, em seu lugar. Em parceria com os professores de filosofia e geografia, já que é uma escola de ensino médio, conversamos sobre a importância de hortas solidarias, isso é, temos uma horta escolar e ensinamos os alunos a plantarem em suas casas, nos espaços possíveis hortaliças e legumes para consumo. Outro destaque que posso comentar com orgulho, é a recolha de latinhas e caixotes para produção de artesanato. Mas, isso se deve a minha esposa, que tem um atelier e as vezes me ajuda para disseminação na escola, como voluntária. ${ }^{11}$

De acordo com as entrevistas realizadas podemos presumir que as escolas públicas carecem de melhorias globais e não apenas pontuais, inviabilizando que trabalhos interessantes sejam desenvolvidos em todo sistema. Ressaltamos que nossa proposta é justamente isso, refletirmos sobre a importância de trazermos para as escolas palestras e cursos de capacitação para os discentes e a comunidade, de forma sistemática e como parte de um currículo com conteúdo optativo.

Esses pequenos exemplos fazem parte de uma teia que pode colaborar na formação de nossos alunos, aproveitando experiências sociais que fazem parte de algum modo, de seu universo, valorizando trabalhos manuais, ideias simples e inovadoras, que podem ser desenvolvidas no contexto

\footnotetext{
${ }^{10}$ Entrevista concedida ao autor em junho de 2015

${ }^{11}$ Entrevista ao autor em março de 2016
} 
escolar, apontando que a sustentabilidade é uma questão de vida ou morte do meio ambiente e por consequência da própria humanidade. E que a educação básica deva ser uma política pública encabeçada efetivamente pelo Governo Federal, e não apenas em intervenções regionais ou paliativas.

\section{CONSIDERAÇÕES FINAIS}

A sociedade deve entender que a educação não pode ser uma mercadoria para empresários de grandes corporações privadas, mas, também não deve se resumir as eternas promessas de campanha política. A luta contra a pobreza e a desigualdade se conecta a alguns ingredientes como programas de inclusão social, saúde, saneamento básico, segurança, empregos formais, defesa do meio ambiente, crescimento econômico e obviamente educação pública de qualidade para todos. 


\section{BIBLIOGRAFIA}

BRASIL, Anna Maria e SANTOS, Fátima. Equilíbrio ambiental \& resíduos na sociedade moderna. São Paulo: Editora FAARTE, 2007.

CATAPAN, A. Discussões sobre os conceitos de sustentabilidade e seus pilares. Latin American Journal of Development, v. 2, n. 6, p. 410-416, 28 Jan. 2021.

CARDOSO, Fatima. Efeito Estufa. SP: Albatroz, Loqui e Terceiro Nome, 2006.

DIAS, Genebaldo Freire. Educação ambiental: princípios e práticas. São Paulo: Gaia, 2004.

FRIEDMAN, Milton. Capitalismo e liberdade. RJ: Nova Cultural, 1982.

GONÇALVES, Carlos Walter Porto. O desafio ambiental. Rio de Janeiro: Record, 2012.

JACOBI, Pedro. Meio ambiente urbano e sustentabilidade: alguns elementos para a reflexão. In: CAVALCANTI, C. (org.). Meio ambiente, desenvolvimento sustentável e políticas públicas. São Paulo: Cortez, 1997.

JOINHAS, SALUN, SANTOS e SILVA. Logística Reversa, sustentabilidade e educação. SP: Todas as Musas, 2013.

MEIHY, José Carlos Sebe Bom. Manual de História Oral. SP: Edições Loyola, 2005.

PÁDUA, S.; TABANEZ, M. (orgs.). Educação ambiental: caminhos trilhados no Brasil. São Paulo: Ipê, 1998.

PELICIONI, Andrea Focesi. Movimento ambientalista e Educação Ambiental. In: PHILIPPI Jr, Arlindo e PELICIONI, Maria C. Focesi (org). Educação ambiental e sustentabilidade. Barueri: Editora Manole, 2005.

PIKETTY, Thomas. O capital no século XXI. Rio de Janeiro: Editora Intríseca, 2014.

SATO, Michele e CARVALHO, Isabel (org). Educação ambiental: pesquisa e desafios. Potro Alegre: Artmed, 2005.

SECRETARIA DE EDUCAÇÃO A DISTANCIA. Cadernos SEAD: Meio Ambiente. Brasília: MEC/SEF, 1998.

SECRETARIA DE EDUCAÇÃO FUNDAMENTAL. Parâmetros curriculares nacionais: introdução aos parâmetros curriculares nacionais. Brasília: MEC/SEF, 1997.

SILVA, Antonio Wardison (org). Educação Ambiental, Étnico-racial e em Direitos Humanos. Americana: Editora Adonis, 2019.

SPOTON, Maria Helena. A arte com fator de inclusão. In: PHILIPPI Jr, Arlindo e PELICIONI, Maria C. Focesi (org). Educação ambiental e sustentabilidade. Barueri: Editora Manole, 2005.

TAJIRI, CAVALCANTI e POTENZA. Habitação Sustentável. Cadernos de Educação Ambiental. V9. Secretaria do Meio AmbientelCoordenadoria de Planejamento Ambiental de São Paulo. SMAICPLA, 2011.

ZIMERMAN, Artur e DIETRICH, Ana (Org). Novas abordagens das políticas públicas no Brasil. Santo André. Ed.UFABC, 2017. 